\title{
PLAN COLOMBIA: ¿ESTADOS UNIDOS ANTE UN NUEVO ENEMIGO EN AMÉRICA LATINA?
}

\author{
Mario Ramírez-Orozco*
}

\begin{abstract}
RESUMEN: Una visión crítica de las consecuencias de la política antiterrorista de Estados Unidos con respecto a América Latina, luego del 11 de septiembre de 2001, demuestra que la implantación del Plan Colombia, bajo el gobierno de Andrés Pastrana y su continuidad durante la administración de Álvaro Uribe, significó no sólo la pérdida de autonomía en la política antinarcóticos sino la narcotización total de la lucha contrainsurgente, con el consecuente escalamiento del conflicto armado que azota a Colombia por varias décadas. Este plan de índole militar propició, además, el intervencionismo directo de Estados Unidos en Colombia y en la región andina y amazónica como una forma de control sobre los grandes recursos naturales, en particular de los yacimientos petroleros de Colombia, Ecuador y Venezuela.
\end{abstract}

Palabras Clave: Plan Colombia; Conflictos armados; Paz; Lucha antiterrorista; Narcotráfico; Bush-Pastrana-Uribe; Guerrillas; Paramilitarismo.

En este trabajo se aborda el problema actual de la violencia en Colombia desde una perspectiva crítica al enfoque oficialista de la mayoría de los trabajos académicos producidos por profesores o funcionarios de entidades estatales colombianas que por desgracia, en parte por intolerancia, consideran inoportuno el cuestionamiento de las políticas gubernamentales con respecto a los movimientos guerrilleros y a las negociaciones para alcanzar la paz. Se cree que criticar el sistema es estar contra él, sin percibir la importancia de compartir diversas opiniones en una sociedad

\footnotetext{
* Programa de Posgrado en Estudios Latinoamericanos, UNAM (riomar@ correo.unam.mx).
} 
acorralada por la violencia en todos sus órdenes. En primera instancia se presenta la introducción del Plan Colombia y los avatares del gobierno de Andrés Pastrana. Luego se hace una valoración crítica de lo transcurrido con el gobierno de Álvaro Uribe. Hay también un enfoque del papel de Estados Unidos con relación a Colombia dentro del espíritu de la cruzada antiterrorista del presidente George W. Bush y del estado actual de las relaciones con los países limítrofes. Al final, unas breves consideraciones.

UN PLAN DE GUERRA PARA ALCANZAR LA PAZ

Desde su llegada a la presidencia Andrés Pastrana (1998-2002) declaró la guerra a las drogas ilícitas y a la insurgencia, rearmando y modernizando de manera considerable las fuerzas armadas y de policía, dejando para los medios de comunicación todo un eficiente manejo demagógico sobre la posible solución negociada con los movimientos insurgentes. Esto muy a pesar de una campaña electoral que presagiaba un gobierno que apostaría por alcanzar la paz y, sobre todo, luego de su histórico encuentro, en julio de 1998, con Manuel Marulanda Vélez, jefe de las FARC-EP (Fuerzas Armadas Revolucionarias de Colombia-Ejército del Pueblo) la más importante guerrilla del país. El presidente Pastrana lanzó el 7 de agosto de 1998 un plan de desarrollo, denominado "Cambio para Construir la Paz 1998-2002”, lo novedoso fue el reemplazo súbito de éste, por uno impuesto por el Departamento de Estado desde Washington. De manera global se estima que este plan utilizará recursos superiores a los US\$7 500 millones, de los cuales US\$3 500 millones se costearan con ayuda exterior. US\$1 600 fueron ofrecidos de antemano por Estados Unidos. ${ }^{1}$

${ }^{1}$ James C. Jones, catedrático de Estudios Internacionales de la Universidad George Washington cuenta que "la versión actual del Plan Colombia llegó a su país (Co- 
Así la burda traducción de un plan elaborado y emitido en Estados Unidos, bautizado como Plan Colombia, hizo especial énfasis en la militarización extrema del país, mientras las causas sociales que obligan a los campesinos pobres a la ilegalidad se atienden de manera marginal. Pocos meses después, ante el avance de la insurgencia política, Estados Unidos intensificó la ayuda contraguerrillera, no sólo con recursos bélicos sino con personal especializado. Este plan fue impuesto, sin que hubiera un debate interno sobre lo efectivo y benéfico de este proyecto, a un país azotado por una tremenda crisis institucional y económica, por la violación sistemática de los Derechos Humanos, por cruentas masacres realizadas por grupos paramilitares de derecha y por la degradación de un conflicto que enfrenta desde hace medio siglo a grupos guerrilleros rebeldes contra los gobiernos liberal-conservadores que monopolizan el aparato estatal durante toda su vida republicana.

Desde su llegada al Palacio de Nariño, y siguiendo un doble juego, el presidente Pastrana, consecuente de algún modo con los anhelos de paz de su electorado, decidió ofrecer a las FARC-EP una zona de distensión de $42000 \mathrm{kms}^{2}$, en cinco municipios de los llanos orientales de Colombia, en un área no muy alejada de la capital del país. Pero, al mismo tiempo, desarrolló una política de reestructuración de las fuerzas

lombia) primero en inglés, no en español. Cuando algunos analistas colombianos compararon la primera versión con la última, se dieron cuenta de que había una diferencia profunda y eso dio lugar a muchos interrogantes. El Plan Colombia que se está aplicando ahora es en realidad un programa de lucha contra las drogas en el cual tiene interés Estados Unidos[...] Es un plan antidrogas, pero también es un plan insurgente”. Cecilia Orozco, ¿Y ahora qué? El futuro de la guerra y la paz en Colombia, Bogotá, El Áncora Editores, 2002, p. 220. De igual manera Julia E. Sweig relata que: "La versión desmantelada que resultó de este Plan Colombia fue un programa de 1300 millones de dólares que se redactó apresuradamente en inglés 'sobre una servilleta a bordo de un avión', como señaló un ex funcionario estadounidense”, “QQué tipo de guerra necesita Colombia?”, Foreign Affairs (en español), otoño-invierno, México, ITAM, 2002. 
armadas y de policía, con grandes inversiones en armamentos y una considerable ampliación del pie de fuerza. La comandancia de las FARCEP aceptó la zona de distensión montó en ella un proyecto de campamentos de paz, con sede central en Villa Nueva Colombia, cerca de la cabecera municipal de San Vicente del Caguán. Zona que durante tres años sirvió para una serie de experimentos de paz, como los denominó la guerrilla. Allí asistieron a dialogar en forma directa con los alzados en armas el presidente Pastrana, en dos ocasiones, dos premios Nobel, el presidente de la bolsa de Nueva York Richard Grasso, los ejecutivos de varias multinacionales, decenas de periodistas extranjeros, diferentes comisiones del senado y la cámara de representantes, políticos de todos los partidos, líderes de los gremios económicos, de los sindicatos, de los estudiantes. Todos quisieron y pudieron conocer de cerca las posiciones guerrilleras y discutir con ellos sobre el futuro de Colombia. Además, había el aliciente de que todos estos encuentros se presentaban por "Señal Colombia", un canal de televisión del Estado con alcance nacional.

Como era de esperar, el balance que sobre la importancia del proceso de paz abierto hicieron los actores del conflicto fue muy diverso y antagónico. Para la clase política gubernamental: “el gobierno Pastrana fue excesivamente generoso con las FARC y que ellos usaron ese proceso de paz, y específicamente la zona de distensión. Que la usaron para reagruparse, entrenarse y armarse". ${ }^{2}$ En el lado opuesto las FARC-EP, en carta de respuesta al parlamento y la conferencia episcopal que les preguntaban sobre la viabilidad de las negociaciones, responden a través de Marulanda Vélez que: "para el Gobierno nada de lo substancial es negociable: referendo, Plan de Desarrollo (de corte neoliberal) y Plan

${ }^{2}$ Declaración del ex consejero de paz del gobierno Ricardo Santamaría, que recoge la opinión generalizada de la clase política bipartidista sobre el proceso de paz y la zona de distensión. En Carlos Holmes Trujillo [ed.], Al oído de Uribe, Bogotá, Editorial Oveja Negra, 2002, p. 27. 
Colombia (sustento para la guerra) son intocables. Así va a ser difícil avanzar en un proceso de paz". 3

Otra opinión, muy generalizada en las ciudades, se sitúa en un lugar crítico que resalta la falta de credibilidad hacia los dos actores principales del conflicto, el gobierno y la guerrilla, en razón de los grandes beneficios que perciben con el mantenimiento de una situación de guerra. La crítica hacia las FARC-EP la resume muy bien el columnista más leído de Colombia, Antonio Caballero, al decir que:

Es natural que no quieran la paz: las FARC viven de la guerra, y gracias a ella están creciendo. Por otra parte piensan que la van ganando. Y lo único preferible para las FARC que el mantenimiento de la guerra es su victoria: pero para lograrla es necesario continuar la guerra. De manera que sus aspavientos sobre el tema de la paz son solamente una farsa. ${ }^{4}$

Unas líneas adelante, Caballero recoge la crítica a la actitud gubernamental:

El establecimiento tampoco quiere la paz por razones parecidas. Porque al menos mientras no la pierda, también le saca provecho a la guerra. Tanto a la guerra misma, que para muchos constituye un excelente negocio, como sobre todo a la situación de injusticia social que es la causa original de que la guerra exista, y que por la propia guerra ayuda a mantener. Pues hemos llegado a un punto en el que solamente la guerra puede garantizar el mantenimiento de esa situación de injusticia, de la cual vive el establecimiento. ${ }^{5}$

En forma paralela al proceso de paz, el presidente William Clinton, a mediados del año 2000, firmó una Ley, que el Congreso de Estados Unidos sancionó, asignando un paquete de asistencia por US\$1 $300 \mathrm{mi}$ -

${ }^{3}$ Semanario Voz, Bogotá, mayo, 2000.

${ }^{4}$ Antonio Caballero, No es por aguar la fiesta, Bogotá, Premio Planeta de Periodismo, 1999, p. 88.

${ }^{5}$ Ibid. 
llones para el Plan Colombia. Casi la totalidad del plan se estructuró de manera que los títulos aparentasen ayudas al desarrollo, mientras los subtítulos detallaban una realidad de aportes a la carrera militarista de los gobiernos de Clinton y Pastrana para Colombia. De una manera sustancial se puede apreciar que el componente más importante del apoyo de Estados Unidos al Plan Colombia es de carácter bélico represivo y apenas es significativo el monto económico para solucionar las causas reales del problema: la marginación de amplias zonas rurales y el paulatino cierre de mercados a los productos lícitos colombianos, luego de la apertura económica de los presidentes Virgilio Barco (1986-90) y César Gaviria (1990-94) que rompieron la producción interna para favorecer la importación de alimentos subsidiados de Estados Unidos y manufacturas y textiles de Asia.

La ayuda de Estados Unidos al Plan Colombia se distribuyó así: 1. Apoyo a los esfuerzos en el sur de Colombia US $\$ 416.9$ millones. 2. Apoyo a los programas de interdicción US $\$ 378.6$ millones. 3. Apoyo a la Policía Nacional de Colombia US $\$ 115.6$ millones. 4. Apoyo al desarrollo económico y alternativo (incluyendo programas nacionales y en el sur de Colombia) US $\$ 106$ millones. 5. Apoyo a programas de promoción de Derechos Humanos y de reforma del sistema judicial Us $\$ 119$ millones. 6. Apoyo a otros programas regionales y al proceso de paz us $\$ 183$ millones. Total del apoyo de Estados Unidos al Plan Colombia US\$1 319.1 millones. $^{6}$

Si se analiza en detalle el aparte que se refiere a "la ayuda de Estados Unidos al Plan Colombia en apoyo al proceso de paz y a la región: us $\$ 183$ millones", se observa que la ayuda concreta al proceso de paz es de apenas US\$3 millones. Los restantes US\$ 180 millones se asignan a planes en otros países de la región como Ecuador y Bolivia, en donde se implementaran con estos recursos el trabajo en las bases militares alter-

${ }^{6}$ PII, Programas de Información Internacional, Departamento de Estado de Estados Unidos, "Descripción del apoyo de Estados Unidos al Plan Colombia" (Servicio Noticioso desde Washington), julio, 2000. 
nas del SouthCom (Comando Sur de Estados Unidos, hoy en Puerto Rico) en Manta, Ecuador, y el Chapare, Bolivia. Es preocupante la inconsistencia de varios puntos. Sólo a manera de ejemplo, cabe preguntar: ¿Qué relación hay entre el proceso de paz colombiano y la "interdicción regional" aérea a la que se le asignan US\$55 millones, o con el supuesto desarrollo alternativo de Bolivia, US\$85 millones, o con los US\$8 millones para la frontera norte de Ecuador, o los US\$32 millones en helicópteros Kmax? Además, hay total falta de claridad sobre si estos equipos operarán sobre Colombia o sólo sobre los otros países. ${ }^{7}$

En general hay una gran distorsión entre la retórica del Plan Colombia, referida a la solución de las causas sociales que obligan a los campesinos pobres a la producción agrícola ilícita, enunciada por los presidentes de Estados Unidos y Colombia, y la intensidad de las medidas represivas y la criminalización extrema de los mismos. Hay que considerar que la represión, siguiendo la complejidad de la cadena del narcotráfico, recae de forma enérgica sobre miserables productores de hoja de coca y flor de amapola, mientras llega de forma marginal sobre los actores más beneficiados económicamente con el tráfico: los distribuidores en el interior de Estados Unidos y Europa. El apoyo de Estados Unidos tiene como interés principal la continuación de la política de satanización de la producción de drogas ilícitas en los países productores, sin afectar de manera eficiente a las cadenas de distribución en el mercado internacional. ${ }^{8}$ Es necesario tener en cuenta que las zonas en donde se concentra la ofensiva del Plan Colombia serían aquellas áreas en donde el control de las guerrillas insurgentes es predominante, mientras se excluyen grandes regiones cocaleras como el Urabá antioqueño y chocoano, Córdoba y la región del Catatumbo en la frontera con Ve-

\section{${ }^{7}$ Ibid.}

8 "Según la DEA, de cada US\$100 pagados por el consumidor estadounidense por la cocaína, quedan 93 en Estados Unidos, 4 ó 5 van a parar al intermediario colombiano y 2 ó 3 quedan para el productor de la hoja de coca", en FARC, el País que proponemos construir, Bogotá, Editorial Oveja Negra, 2001, p. 48. 
nezuela, lugares en los que el control territorial es casi exclusivo por parte de grupos paramilitares. ${ }^{9}$

La reiterada violación de los derechos humanos por parte de los gobiernos colombianos que de manera selectiva recae sobre la población civil de las áreas de influencia de los grupos políticos legales de izquierda o de las guerrillas de la misma tendencia política, sigue sin ser tomada en cuenta como lo exigen las comisiones de derechos humanos de la ONU y la OEA u organismos como Amnistía Internacional, Human Rights Watch, Pax Cristhi, Serpal, etc. ${ }^{10}$ Un hecho determinante es que en la Ley 106-246, firmada por el presidente de Estados Unidos, William Clinton, en julio de 2000, en su artículo 3201 introducía exigencias relativas a los derechos humanos como condición previa para otorgar ayuda militar a Colombia. Sin embargo un mes después, el 22 de agosto de 2000, el mismo Clinton invocó la sección 4 del mismo artículo 3201, el que permitía dejar al margen las condiciones relativas a la supervisión de los derechos humanos en Colombia. Desde entonces es el presidente estadounidense quien determina de forma discrecional cuándo se puede pasar por alto la violación de los derechos humanos en provecho de la seguridad nacional de Estados Unidos.

9 “[E]n esta presentación del Plan se toma como meta la reducción del cultivo, procesamiento y distribución de la droga en un 50\%, para la cual se busca "establecer control militar sobre el sur del país con propósitos de erradicación” y "restablecer el control gubernamental sobre las áreas claves de producción de droga". La pregunta obvia es si al establecer control militar en el sur del país: “¿no se piensa restablecer el control militar en las áreas bajo la influencia paramilitar?” De la carta dirigida a Santiago Montenegro, director de Planeación Nacional, por Fernán González, Director del CINEP, Bogotá, 16 de junio, 2000.

${ }^{10}$ En los últimos años, más de 300000 nuevos refugiados fueron obligados a salir de sus regiones, con un saldo de alrededor 3000 muertes y varias masacres horribles. En su mayoría las fuerzas paramilitares, cercanas a las autoridades militares de estas regiones han sido señaladas como las autoras de estos actos de intimidación y violencia. Véanse los documentos sobre estos hechos emitidos por Human Rights Watch en febrero de 2000 y el de abril del mismo año realizado por la Comisión de Derechos Humanos de la ONU. 
El 20 de febrero de 2002, el presidente Andrés Pastrana de manera unilateral rompió los diálogos con las FARC-EP y declaró objetivo militar la zona de distensión. El secuestro de un avión y la retención de un parlamentario sirvieron como pretexto para el rompimiento. Todo indica que la decisión de Pastrana se venía madurando de tiempo atrás y, para nadie fue un secreto, que el incidente era la simple excusa para quedar bien con las presiones de los candidatos más votados, el liberal oficialista Horacio Serpa y el liberal disidente Álvaro Uribe, quienes habían reducido su estrategia electoral al supuesto fracaso del gobierno en las mesas de negociación y pedían el cese de la zona de distensión por considerar peligrosos los avances guerrilleros en materia política. Las mesas temáticas y el continuo viaje de personalidades nacionales y extranjeras a entrevistarse con el secretariado de las FARC-EP creaba un precedente que debería culminar. En términos del proceso de paz, el gobierno Pastrana trabajó como ya se dijo con una estrategia doble: "hicimos un proceso de paz genuino pero no ingenuo", 11 dijo el presidente; mientras su consejero de paz Camilo Gómez mostró las cartas del juego: "a la vez que se buscaba la negociación política también se adelantaba el fortalecimiento de las fuerzas armadas". ${ }^{2}$ Obtuvo así un triunfo relativo a mediano plazo: la modernización del aparato militar. En lo político, el fracaso fue rotundo en la medida que cerró la confianza entre actores que buscan la paz por la vía política. En apariencia la propuesta de paz de Pastrana fue generosa, al ceder una zona de distensión a la guerrilla y permitir el acceso de varios sectores para mantener conversaciones directas con los jefes guerrilleros, sin embargo la estrategia que le dio mejores resultados fue la reestructuración de las fuerzas armadas:

según datos oficiales, el pie de fuerza creció $38 \%$ (bachilleres, conscriptos y profesionales) y en $141 \%$ el número de soldados profesionales. Los

${ }^{11}$ Holmes Trujillo op. cit., p. 17.

12 Ibid., p. 110. 
soldados combatientes pasaron de 80000 en 1998 a 140000 a finales de este año. Aumentó en $300 \%$ el número de helicópteros artillados y en $114 \%$ el de helicópteros de transporte. Las brigadas móviles pasaron de tres a siete. La policía creó 26 frentes de seguridad con 1.3 millones de integrantes. ${ }^{13}$

De forma paradójica, con la implementación del Plan Colombia, la producción de coca y amapola aumentó hasta casi 180000 hectáreas a pesar del fuerte avance militar, la política de represión y fumigaciones y por los grandes recursos sociales desviados para este fin. Además, los movimientos guerrilleros al finalizar el gobierno Pastrana, en agosto de 2002, habían crecido de forma sustancial: las FARC-EP, con cerca de 30000 hombres, entre guerrilleros y milicianos; el Ejército de Liberación Nacional, ELN, más o menos 5 000, y los grupos paramilitares, las Autodefensas Unidas de Colombia, AUC, entre 10000 y 12000 hombres armados. ${ }^{14}$ En materia de violencia el panorama fue también desalentador: más de 72 muertes violentas al día, más de 26000 al año; cerca de 3000 secuestros anuales y el alarmante incremento de desplazados internos que supera el millón y medio de personas. ${ }^{15}$

\section{AUTORITARISMO PARA LA GUERRA}

En la campaña a la presidencia colombiana 2002-2006, un fenómeno político sacudió de manera formal la hegemonía del bipartidismo Liberal-Conservador: el sorpresivo triunfo en la primera vuelta del disidente

13 "El proceso de paz no fracasó", Revista Cambio, Bogotá, 21 de julio, 2002.

14 Informe anual de la Fundación País Libre, Bogotá, 2002.

15 Datos del Capítulo I, "Brindar seguridad democrática" de las Bases del Plan Nacional de Desarrollo, Bogotá, Presidencia de la República, agosto, 2002. Según el CODHES, desde 1985 hasta el año 2000, han sido desplazados de sus lugares de origen, como consecuencia del conflicto armado, 2160000 colombianos. 
del partido Liberal, Álvaro Uribe Vélez. Durante la toma de posesión del nuevo presidente, el 7 de agosto de 2002, Colombia estaba más lejos de una salida negociada que en agosto de 1998. Mientras Andrés Pastrana fue elegido bajo las banderas de la paz, se puede afirmar de manera categórica que el nuevo presidente fue elegido para un mandato de guerra.

Uribe, quien centró su campaña en dos lemas: "Ganarle la guerra a la guerrilla" y "Sin seguridad no habrá crecimiento, bienestar ni empleo", al llegar al Palacio de Nariño presentó: "un modelo integral de Seguridad Democrática que le permitiría al Estado recuperar la autoridad con criterios de legitimidad, legalidad y gobernabilidad."16 En consecuencia, bajo la premisa de la necesaria recuperación de autoridad estatal debido a que "la Nación entera está sometida a un régimen de terror en el que naufraga la autoridad democrática", su primer acto de gobierno, a menos de una semana de su posesión, fue la expedición del Decreto número 1837 de 2002, que declara el Estado de Conmoción Interior. Esta declaratoria, en esencia guerrerista, culpa de manera tácita a la política de paz de Pastrana como la responsable de que "Hemos alcanzado la más alta cifra de criminalidad que en el planeta se registra, en un proceso acumulativo que hoy nos coloca a las puertas de la disolución social." 17

El nuevo presidente hizo énfasis también en la creación de nuevos impuestos para aumentar el número de efectivos de las fuerzas armadas y de policía. Amplió el periodo del servicio militar obligatorio y fomentó la creación de "mecanismos de cooperación ciudadana y en especial faculta la organización de redes [civiles] que a través de la Policía Nacional o de la Fuerzas Militares, según el caso, cooperen de manera activa para prevención del delito y de los actos terroristas tanto en las

16 Álvaro Uribe Vélez, Plan Nacional de Desarrollo, Bogotá, Presidencia de la República, agosto, 2002.

${ }^{17}$ Estado de Conmoción Interior, Decreto 1837 de 2002, Bogotá, Presidencia de la República, agosto, 2002. 
zonas urbanas como rurales". El agravante a esta última propuesta es que el presidente Uribe tiene el antecedente nefasto de haber impulsado a Las Convivir, grupos de autodefensa legales impulsados durante su gobernación en el departamento de Antioquia y que luego serían la base de los grupos paramilitares responsables de cientos de masacres. ${ }^{18}$

Instauró un polémico programa de informantes para delatar ante las autoridades militares a los colaboradores de los grupos insurgentes o criminales. Fomentó las recompensas económicas por la delación y creó en las zonas más violentas del país un insoportable clima de desconfianza entre los vecinos. Este tipo de medidas, en un país tan polarizado como Colombia, se utiliza como arma política en contra de los opositores y en incremento de la violación de los derechos fundamentales. ${ }^{19} \mathrm{~A}$ los medios de comunicación el presidente Uribe les exigió "acuerdos de autorregulación orientados a atenuar el impacto de las acciones terroristas en la opinión pública". El problema es que dicha "autorregulación" casi siempre está determinada por las autoridades militares de las zonas en donde la violencia política es predominante..$^{20}$

18 Julia E. Sweig, “QQué tipo de guerra necesita Colombia?”, Foreign Affairs (en español), otoño-invierno, México, ITAM, 2002.

${ }^{19}$ Punto 28 del Capítulo I de las Bases del Plan Nacional de Desarrollo: "i. Redes de cooperación./Este esquema de apoyo estará constituido por un millón de ciudadanos en las zonas rurales y urbanas del territorio nacional, quienes participarán voluntariamente en redes de cooperación./ ii. Programas de recompensas/De manera paralela, el Gobierno Nacional implementará un programa de recompensas para los informantes que proporcionen a las autoridades datos oportunos y veraces sobre personas, bienes o actividades relacionadas con los grupos armados ilegales y la delincuencia. En adición a todo lo anterior, se buscará el desarrollo legal del artículo 441 del Código Penal, que establece la obligación de los ciudadanos de informar inmediatamente a la autoridad sobre el conocimiento de cualquier indicio, actividad o persona relacionados con actos delictivos y de terrorismo." En departamentos como Antioquia es frecuente que en los medios de comunicación aparezcan las autoridades regionales entregando fuertes sumas de dinero a delatores enmascarados. Diario El Colombiano, primera página, Medellín, 12 de noviembre, 2002.

${ }^{20}$ En principio dicha medida parece innecesaria en Colombia en donde todos los principales medios de comunicación son oficialistas. Como ejemplo, hay que recordar 
En definitiva, el presidente Uribe centró su política de Estado en una llamada "Seguridad Democrática", lo que significó apoyar con decisión la continuidad de todos los programas del Plan Colombia; una gran inversión en el aparato militar, para el fortalecimiento de las instituciones represivas y de inteligencia. Además, desde su primer discurso el 7 de agosto de 2002, pidió el sacrificio en materia de inversión social, a un país que esperaba más atención a los graves problemas de marginación y miseria de la mayoría de la población colombiana. Archivó su programa de campaña, con "Mano firme y corazón grande", en el que reconocía los graves problemas de desigualdad e injusticia social, aunque presentaba soluciones inviables o poco relevantes a corto o mediano plazo, a problemas tan concretos como la corrupción en el Congreso, con la propuesta de reducir las dos cámaras a una y con la baja de salarios y el impedimento a la utilización en politiquería de los auxilios parlamentarios. ${ }^{21}$ También propuso una "revolución educativa" y cuestionables planes de creación de empleo, en un país con una tasa de casi $17 \%$ de desempleo, sin contar el alto porcentaje de subempleo o desempleo disfrazado.

Con respecto a la solución negociada del conflicto, el presidente Uribe afirma en su Plan Nacional de Desarrollo que "La vía del diálogo en medio del conflicto está agotada." Y, más adelante, agrega: "La paz no se negocia, se construye." 22 El problema es que su construcción de

que en este país de más de 40 millones de habitantes no hay otra alterativa informativa de alcance nacional que el diario El Tiempo; y donde la concesión de los noticieros de televisión son por tradición una prebenda a los hijos de los ex presidentes del país o jefes políticos. Fue el caso de Andrés Pastrana. Además, hay que tener en cuenta que en materia de seguridad y orden público en Colombia se entiende por información a la publicación acrítica de los boletines de la oficina de prensa de la Presidencia de la República y a los comunicados expedidos por las autoridades militares.

${ }^{21}$ Debido al fuerte ataque con cohetes a la sede presidencial por parte de las FARC-EP, y que por poco convierten en tragedia su toma de posesión el 7 de agosto de 2002, Uribe no encontró en las primeras semanas mayores críticas a su estrategia guerrerista.

22 Punto 57 del Capítulo I de las Bases del Plan Nacional de Desarrollo. 
paz está basada en una estrategia de guerra y exterminio del opositor político. Uribe ha creado en algunos sectores la falsa ilusión de la posible derrota militar de las guerrillas, lo que haría innecesario cualquier diálogo o negociación de paz. Sin embargo, a casi dos años del inicio de su mandato, estas expectativas se han esfumado por una realidad que muestra que los avances oficiales de aniquilación de las fuerzas guerrilleras son mínimos. Es de notar que "construir la paz" es una frase que como reclamo publicitario suena bien, pero que para un país como Colombia no dice mucho teniendo en cuenta que, como en el Medio Oriente, desde hace medio siglo este país ha estado en una situación permanente de construcción de paz.

Un grave error de Uribe es desconocer que el problema de la paz no se puede abordar de la misma forma como durante el gobierno de Belisario Betancur (1982-1986), pues tanto el país como la insurgencia son otros. Fue válido que el Estado liberal-conservador y sus gobiernos aceptaran su responsabilidad histórica en las llamadas "causas objetivas" de la violencia, como caldo de cultivo de los distintos grupos insurgentes. Por eso las políticas de paz enfocadas en la autocrítica y rectificación de los errores cometidos por las clases dirigentes y sus gobiernos cumplieron un útil papel para que guerrillas antigubernamentales como el M-19 y otras más pequeñas aceptaran su desmovilización y decidieran participar en el debate electoral abierto, confiadas en que dentro del sistema ayudarían a que el Estado rectificara e hiciera de Colombia una sociedad más justa y democrática. ${ }^{23}$

${ }^{23}$ El modelo de Acuerdo de Paz firmado por el M-19 y otras agrupaciones desmovilizadas en 1991 se basa en la aceptación de estas guerrillas de "la legalidad imperante"; mientras que para las FARC-EP: "una negociación de paz no puede desconocer este [el] poder regional que han ganado a lo largo de los años ni dejar de ofrecer los medios de consolidar las frágiles economías campesinas propias de las zonas de colonización”. Citas en Mauricio García Durán, De la Uribe a Tlaxcala. Procesos de Paz, Bogotá, CINEP, 1992, p. 54. 
Pero los cambios que el país necesitaba para aliviar el gran descontento social no fueron suficientes. A pesar de una nueva Constitución Política (1991), muy progresista en el papel, y de una supuesta Circunscripción Especial de Paz, al M-19 y al EPL; los asuntos fundamentales como la tenencia de la tierra, la participación política con igualdad de garantías y el fin del bipartidismo excluyente nunca fueron considerados. Luego, motivados por la falsa percepción de que el movimiento armado perdería su moral de lucha ante los graves sucesos como la desintegración de la Unión Soviética, el cambio de régimen de los países socialistas de Europa del Este y la debilidad económica de Cuba, los gobiernos de Virgilio Barco (1986-1990) y de César Gaviria (1990-1994) decidieron cerrar los espacios políticos a las FARC-EP, para esperar su pronta desintegración. ${ }^{24}$ Sin embargo, a pesar del duro golpe para todos los movimientos de izquierda en el mundo por lo sucedido con el bloque socialista, la realidad se encargó de demostrar que las causas internas del problema colombiano eran suficientes para mantener en alto las banderas de lucha. Más aun cuando estos presidentes incentivaron las políticas neoliberales que acabaron de manera sustancial con la producción manufacturera y agrícola del país y llevaron la pobreza a más población.

Así, para desgracia de todos los colombianos, las guerrillas antisistémicas, como las FARC-EP y el ELN, sintieron que el modelo de paz utilizado con el M-19, el EPL y otras pequeñas guerrillas sólo cumplió un papel importante de neutralización de las luchas populares, en particular las urbanas, por lo que consideraron que tal modelo no podía seguir siendo la camisa de fuerza como la utilizaron en los diálogos de paz los gobiernos de Samper y Pastrana. Sobre todo teniendo en cuenta la

${ }^{24}$ A manera de estocada final, César Gaviria llegó al extremo, el 9 de diciembre de 1990, día en el que se realizaban las elecciones para elegir a los participantes en la Asamblea Nacional Constituyente en Bogotá, de efectuar un intenso bombardeo sobre Casa Verde, sede del Estado Mayor de las FARC-EP. 
agudización de la precaria situación económica de un porcentaje muy grande de la población, el aumento de la represión a los militantes legales de izquierda, como los de la Unión Patriótica, UP, y la exclusión de grandes sectores de las oportunidades de educación y trabajo. ${ }^{25}$

\section{LA PRIORIDAD DEL CANJE}

Desde comienzos de 2003, las FARC-EP se han replegado y, salvo las escaramuzas propias de los encuentros con fuerzas oficiales, sus operaciones ofensivas son mínimas. Su política actual ha sido la implementación de una campaña por el intercambio humanitario de más de 3000 prisioneros o retenidos políticos por los guerrilleros de las FARC-EP detenidos en las cárceles del Estado. Entre los canjeables se destacan una ex candidata presidencial, algunos ex ministros y parlamentarios; lo mismo que más de 800 soldados y policías. La posición de Uribe al respecto ha sido intransigente al plantear que la entrega debe ser voluntaria y sin ninguna contraprestación, tratando con cierta arrogancia el clamor de los familiares de los retenidos y de un amplio sector de opinión que se expresa a favor del cambio humanitario. Su punto de vista es claro: "la política de orden público debe estar por encima del afán por el intercambio humanitario". ${ }^{26}$ Ha sido tal la obsesión de Uribe de impedir el canje humanitario que en repetidas ocasiones ha declarado que: "ni las crisis y ni las presiones lo van a mover de su línea establecida", esto a pesar de que sus fallidos intentos de rescatar por medios militares a los retenidos ha significado la muerte de varios rehenes, entre ellos el ex ministro de Defensa y ex consejero de Paz, Gilberto Echeverry y

${ }^{25}$ Entre 1987 y 1992, más de 4500 dirigentes y militantes de la Patriótica (UP) y el Partido Comunista de Colombia (PCC), fueron asesinados por paramilitares y militares en activo, incluyendo los candidatos presidenciales de la UP, Jaime Pardo Leal y Bernardo Jaramillo, varios de sus parlamentarios y alcaldes.

26 "Editorial”, Diario El Tiempo, Bogotá, 7 de mayo, 2003. 
el Gobernador del departamento de Antioquia Guillermo Gaviria, el 5 de mayo de $2003 .{ }^{27}$

El intercambio humanitario, en otras circunstancias un asunto de orden secundario, se ha convertido en tema prioritario en la administración Uribe debido al importante papel que puede jugar como llave para abrir o cerrar las negociaciones de paz. El propio Marulanda Vélez de las FARC-EP se ha encargado de manera personal del tema; pues para ellos lograr el intercambio implica el restablecimiento de estatus político, de fuerza beligerante, y la posibilidad de ser tratados de nuevo como un actor político no terrorista ni narcotraficante. El 27 de abril de 2003, al encontrar cerradas todas las posibilidades de comunicación con el presidente Uribe, el Estado Mayor Central envió una carta a los ex presidentes Alfonso López, Julio César Turbay, Ernesto Samper y Carlos Lemos en donde declaraban que las FARC-EP "están dispuestas a dejar en libertad a todos los militares y policías en su poder, los doce diputados del Valle del Cauca, los dos ex ministros de Estado, el Gobernador de Antioquia, el ex gobernador del Meta y la ex candidata presidencial Ingrid Betancourt." 28 Por su parte, la respuesta de todos los ex presidentes fue positiva, Alfonso López y Ernesto Samper expresaron que:

[el intercambio] era un imperativo y una decisión ineludible, cuyo soporte jurídico está en el Derecho Internacional Humanitario, suscrito por Colombia e integrante por ende del sistema constitucional colombiano. En opinión de López Michelsen no se requiere una ley que autorice al gobierno para el acuerdo humanitario, sino que se trata de un tema de voluntad política. ${ }^{29}$

Pero, como anotaba antes, para desgracia de varios rehenes, la actitud guerrerista del presidente Uribe les costó la vida. El rescate fallido

27 Ibid.

${ }^{28}$ En Carta enviada a los ex presidentes por el Secretariado del Estado Mayor Central de las FARC-EP, Montañas de Colombia, 27 de abril de 2003.

${ }^{29}$ Niko Schvarz, Diario La República, Montevideo, 2 de mayo, 2003. 
realizado por una fuerza élite del ejército, muy mal preparada, no sólo tenía como objetivo principal la liberación de los rehenes sino la misión de impedir, con su probable éxito, cualquier posibilidad de canje humanitario durante su mandato de los retenidos por la guerrilla (inclusive de tres agentes de la CIA, apresados cuando ejercían funciones de inteligencia para el gobierno colombiano), por los guerrilleros presos, casi todos en condiciones infrahumanas y juzgados en procesos jurídicos que no cumplían las más elementales normas del derecho.

\section{EL PARAMILITARISMO, UNA VÍA REITERADA}

En sus discursos los presidentes Pastrana y Uribe han insistido en la falta de apoyo popular de las FARC-EP y el ELN desconociendo que siguen teniendo un control territorial de casi el $40 \%$ del territorio colombiano y son percibidos por la población de esas zonas como las únicas autoridades legítimas. La intensificación de los operativos militares en las regiones en donde tienen su base civil parecen desmentir esas afirmaciones y más bien el desmesurado aumento de las fuerzas paramilitares coincide con la campaña gubernamental de exterminio del apoyo civil al movimiento guerrillero. Organismos de derechos humanos han denunciado la participación conjunta del ejército con grupos paramilitares, muy al estilo de los escuadrones de la muerte utilizados por las dictaduras del Cono Sur o por los regímenes de El Salvador y Guatemala, o aún mejor, debido a la magnitud y organización similares a la "contra" nicaragüense, lo que ha propiciado la denuncia de la Comisión de Notables, conformada por el gobierno y las FARC-EP, al señalar:

[...] constatamos, con viva preocupación, que en estos tres años de iniciado el proceso, bajo el esquema de la negociación bajo la guerra, el conflicto lejos de amainarse se ha intensificado, y el paramilitarismo no ha cesado de aumentar su accionar ilegal. Como consecuencia de ello, cada día aumentan el número de masacres y de víctimas inocentes y las violaciones más aberrantes al Derecho Internacional Humanitario (DIH) [y en 
consecuencia recomiendan en el punto F] Que se continúe, al interior de las Fuerzas Armadas y de Policía el proceso de desvinculación de todos aquellos individuos que hayan resultado comprometidos en actividades de tipo paramilitar o sobre los cuales haya serios indicios de estarlo, sin perjuicio de que contra ellos se adelanten los procesos judiciales y disciplinarios correspondientes, con el propósito de evitar que tales conductas queden en la impunidad. ${ }^{30}$

Asimismo organismos de derechos humanos internacionales, como es el caso del Alto Comisionado de las Naciones Unidas para los Derechos Humanos aseveran en su informe de 2003 que: "El paramilitarismo siguió siendo un factor desestabilizador del Estado de derecho, en particular por los vínculos que con él mantienen servidores públicos y por la inconsistente respuesta estatal a este fenómeno." ${ }^{31}$

\section{III}

\section{DEL PLURALISMO DIPLOMÁTICO A LA AGENDA BUSH}

Desde el momento mismo de asumir como presidente, Álvaro Uribe dejó en claro la continuidad de las buenas relaciones sostenidas por Andrés Pastrana con Estados Unidos, ratificando al embajador Luis Alberto Moreno, por considerarlo el artífice de la reconstrucción diplomática después del grave deterioro en las relaciones del gobierno de Ernesto Samper. Como candidato Uribe se comprometió en visita a Washington a la implementación del Plan Colombia y una segura aprobación de su gobierno al polémico artículo 98, el que permitiría la impunidad a los

30 "Recomendación de la Comisión de Notables a la Mesa de Diálogo y Negociación", septiembre de 2001.

${ }^{31}$ En abril de 2003, el Alto Comisionado de las Naciones Unidas para los Derechos Humanos presentó un detallado informe sobre la situación de los derechos en Colombia a la Comisión de Derechos Humanos de dicho organismo. 
cada vez más numerosos asesores de Estados Unidos, quienes participan ya en acciones de combate directo contra las guerrillas de las FARCEP. ${ }^{32}$ La presión en esta materia es tan evidente por parte de Estados Unidos que Phil Chicola, uno de los responsables de la Oficina de Asuntos Andinos que funciona en la órbita de la Subsecretaria para el Hemisferio Occidental en el Departamento de Estado dijo que era prioritario para Colombia el firmar este artículo en razón de la cada vez más necesaria presencia de fuerzas de marines en el país para combatir a las narcoguerrillas. ${ }^{33}$

Hay en el presidente Uribe un desmedido interés en colocar el conflicto colombiano dentro de un orden internacional acorde con la política antiterrorista de Estados Unidos, implementada luego del 11 de septiembre de 2001. Para él no es correcto dejar a Colombia fuera de los países víctimas del "mal" y cree que se debe "afganizar" a Colombia, combinando el avance de las fuerzas armadas colombianas con un número ilimitado de tropas terrestres de Estados Unidos: "Nuestro aliado natural en este área son los Estados Unidos. No hablamos de soldados. Hablamos de [más] helicópteros, entrenadores, tecnología y dinero." 34 Uribe insiste en foros nacionales e internacionales en la conveniencia de ver como similares los casos de Colombia e Irak y pide que: "el mundo democrático venga a Colombia a ayudarnos a derrotar el terrorismo. Necesitamos que así como se está dando en Naciones Unidas una discusión sobre el caso Irak, el mundo tome la decisión de ayudar a

32 Véase declaración del presidente Uribe en la primera página del diario El Tiempo, 5 de mayo de 2003, en la que reconoce que las fuerzas élite de Estados Unidos ya no sólo participan como fuerzas de apoyo sino en acciones de choque directo. Con la firma del artículo 98 Colombia se obliga a no entregar a la Corte Penal Internacional, de la que es miembro fundador, a ningún militar o funcionario de Estados Unidos que haya cometido algún delito en el territorio de Colombia, en funciones de servicio o no, sin el aval de las autoridades de Washington.

${ }^{33}$ Esto lo afirmó Phil Chicola en una conferencia conjunta con el presidente Uribe en el Carneggie Endowment de Washington, D.C., el 25 de septiembre de 2002.

${ }^{34}$ Newsweek International, 25 de marzo, 2002. 
Colombia", desconociendo las diferencias entre los orígenes y circunstancias de las realidades de estos dos países. ${ }^{35}$

La participación o intervención de Estados Unidos en los asuntos internos de Colombia se ha intensificado desde la introducción del Plan Colombia, en 1999, por los presidentes William Clinton y Andrés Pastrana, cuando Colombia se convirtió en uno de los principales receptores por parte de Estados Unidos de armamentos pesados y semipesados, entrenamiento de fuerzas élite y de asesoría en inteligencia militar, junto a Turquía, Israel y Egipto. Esta política de militarización extrema de Colombia fue refrendada en 2002 por los nuevos presidentes George W. Bush y Álvaro Uribe. No hay duda que, como marco de fondo, fueron relevantes los hechos del 11 septiembre de 2001, al servir de pretexto para que el Congreso recibiera la propuesta del presidente Bush de quitar del Plan Colombia cualquier cláusula que impidiera ver la asociación de intereses entre las mafias del narcotráfico y los grupos insurgentes, al colocar en la agenda a los grupos armados guerrilleros y paramilitares que el Departamento de Estado considera en su lista de terroristas internacionales. ${ }^{36}$ Así la guerra al narcotráfico se convirtió en bicéfala, con una cabeza que ataca a las mafias de las drogas y otra dirigida contra la insurgencia política; con la peligrosa tendencia, entre los defensores a ultranza de la política de contrainsurgencia, de colocar un orden de prioridades para combatir a los enemigos, primero a las FARC-EP, a pesar de saber que las AUC son de lejos los principales violadores de los derechos humanos en Colombia, pues consideran de manera ingenua que el problema de los paramilitares se resolverá al instante

${ }^{35}$ En declaración del presidente Álvaro Uribe Vélez luego del atentado dinamitero contra el club social El Nogal en Bogotá, 8 de febrero, 2003, en (http://www. presidencia.gov.co/discursos/archivogen.htm).

${ }^{36}$ Un análisis serio no deja percibir que tanto las izquierdistas FARC-EP y el ELN, como las derechistas AUC, sean un peligro real más allá de los límites de Colombia, pues en sus años de lucha armada nunca han actuado fuera de sus fronteras. Las pocas ocasiones en las que han actuado contra personas u objetivos de Estados Unidos han sido todas en territorio colombiano. 
mismo en el que se derroten o negocie con las FARC-EP. Sostienen que hay que combatir sólo a las FARC-EP, en razón de su posición antisistémica.

El Secretario de Estado Adjunto para Asuntos del Hemisferio Occidental, Otto J. Reich, ratificó la importancia del caso colombiano en la agenda de su gobierno al afirmar que: "Colombia puede derrotar a los terroristas, pero necesita ayuda de sus amigos para lograrlo. Nuestros valores, nuestra seguridad y el futuro de nuestro Hemisferio están ligados a la victoria de Colombia en su guerra contra el terrorismo." Más adelante señaló que: "nuestros intereses en el éxito de la democracia colombiana son grandes, el presidente Bush le pidió al Congreso autorizarnos para proporcionar ayuda militar y de inteligencia al gobierno colombiano para su guerra contra el terrorismo". ${ }^{37}$ Una semana más tarde en el programa de televisión "Foro Interamericano", de la Voz de América, Reich fue mucho más explícito respecto a la política de seguridad que Estados Unidos tiene planeada para Colombia en relación con los grupos que el Departamento de Estado considera narcoterroristas: "representan una amenaza no sólo para la democracia colombiana, sino para toda la región". Aprovechó la ocasión para hablar en términos geopolíticos, al señalar que no es posible considerar a la región andina como una zona aislada de Centroamérica, el Amazonas y las salidas estratégicas del Canal de Panamá al Pacífico y al Caribe. Concluyó que debe ser prioritario el apoyo de todos los países de la región al gobierno colombiano en esta lucha, y para ello Estados Unidos ponía el ejemplo con el incremento de ayuda militar. ${ }^{38}$ Sin embargo, en la actualidad, y lejos de la opinión de Otto Reich, desde una perspectiva geopolítica mundial, el caso colombiano es marginal, pues sólo parece importar a mediano y largo plazo a la política exterior de Estados Unidos. Es signi-

37 The Washington Times, 19 de julio, 2002.

${ }^{38}$ En el programa de televisión "Foro Interamericano" de la Voz de América. Washington, 26 de julio, 2002. 
ficativo que a finales de marzo de 2003, durante la invasión a Irak, el presidente George W. Bush, de forma algo arbitraria, incluyera en una solicitud de ayuda antiterrorista para Irak a Colombia.

\section{LA CONTENCIÓN DEL CONFLICTO}

A nivel regional lo que acontece en términos políticos en países como Brasil (1 645 kms. de frontera con Colombia), Ecuador (586), Panamá (266), Perú (1 625) y Venezuela (2 219), es muy importante para la situación interna colombiana. Además del histórico diferendo limítrofe con Venezuela, la llegada al poder de Hugo Chávez ha creado tensión en las relaciones entre estos dos países por la coincidencia de discurso antiimperial y bolivariano con las FARC-EP. Lo mismo podría decirse desde que asumió la presidencia de Ecuador el ex militar Lucio Gutiérrez, quien sin ser tan radical como Chávez, pidió una revisión de los acuerdos en materia de seguridad con Estados Unidos. Panamá es un vecino incómodo que lucra con el lavado de dinero y con el tráfico internacional de armas, al tiempo que actúa como muro de contención para miles de refugiados que huyen de la violencia colombiana; Perú, envuelto en problemas de gobernabilidad del presidente Toledo, opta por la cautela en su relación con Colombia luego de los agitados años de Fujimori y Montesinos en el poder. Sin descontar el peso específico para la región de un presidente en Brasil de tendencia izquierdista como Ignacio Lula da Silva. ${ }^{39}$

Ecuador es la frontera con Colombia en donde el conflicto se vive con mayor intensidad, en ella está uno de los dos departamentos, el Putumayo (el otro es Caquetá), prioritarios en el Plan Colombia. Las escaramuzas provocadas por los enfrentamientos entre guerrilleros y

39 James Petras, La geopolítica del Plan Colombia, La Habana, Siglo XXI, 2001, p. 3. http://www.cubaxxi.f2s.com/ 
paramilitares colombianos han dejado una secuela de intranquilidad en las provincias ecuatorianas fronterizas con Colombia. En poco tiempo Ecuador se ha convertido en un importante centro de abastecimiento para todas las fuerzas irregulares de Colombia. El dinero del narcotráfico han cambiado por completo la actitud de la población y las autoridades ecuatorianas. Ya es un hecho que Ecuador vive la doble situación de beneficiarse de dinero del narcotráfico y padecer las secuelas del deterioro del orden público. Por ahora Ecuador maneja con prudencia la idea de tomar parte en cualquier grupo de países que se involucren de manera directa en el problema colombiano. Jaime Marchán, viceministro de Relaciones Exteriores, afirmó que: "el conflicto colombiano debe ser resuelto por las autoridades de esa nación".

Sin embargo, Ecuador observa con inquietud todo el acontecer colombiano, pues teme que el conflicto armado traspase la frontera e involucre a sectores inconformes de su país en un levantamiento más organizado que el del 21 de enero de 2000. Además, ven con preocupación que se cree un desequilibrio demográfico por el creciente número de familias colombianas que se desplazan como refugiados a las provincias fronterizas. Corroborando la no ingerencia del Ecuador, y haciendo un desplante a la insinuación de la cancillería colombiana, Octavio Romero, jefe del ejército ecuatoriano, es claro al afirmar que las fuerzas armadas de Ecuador serán neutrales ante el conflicto colombiano. Lo que no descarta el necesario reforzamiento de las medidas preventivas para impedir el paso a territorio ecuatoriano de las fuerzas irregulares guerrilleras o paramilitares de Colombia. ${ }^{40}$ Los medios de comunicación ecuatorianos reiteran que hay inquietud en torno al papel que cumple la base militar de Manta y la presencia de un número preocupante de asesores militares de Estados Unidos en el país. En los últimos tres años Ecuador ha aumentado el pie de fuerza en la zona fronteriza con Colom-

${ }^{40}$ IPS, Quito, 27 de febrero, 2003. 
bia y ha cerrado por periodos cada vez más prolongados el paso por el puente internacional de Rumichaca. ${ }^{41}$

En Washington, en febrero de 2003, el ex coronel Lucio Gutiérrez, nuevo presidente ecuatoriano le dijo de manera un tanto sorpresiva a George W. Bush, si se tiene en cuenta que uno de los estandartes de su éxito electoral fue la reivindicación nacionalista y antiemperialista: “[...] que queremos convertirnos en el mejor aliado y amigo de Estados Unidos, en la lucha por la paz en el mundo, por fortalecer la democracia, por reducir la pobreza, por combatir el narcotráfico y por acabar con otra lacra, el terrorismo". ${ }^{42}$ Como premio a estas declaraciones el mandatario ecuatoriano llegó a Quito una ayuda extraordinaria de US\$116 millones. ${ }^{43}$ Más tarde, en una conferencia en el Centro de Estudios Estratégicos Internacionales, aseveró en relación a Colombia que: "Si no apoyamos, todos, de manera más protagónica a Uribe, seguramente se seguirá sacrificando la vida de más gente". Así las cosas, el temor del presidente Uribe de que su frontera sur le creara problemas a la implantación del Plan Colombia o al Plan Andino parece desvanecerse luego de la visita de Gutiérrez a Bush.

Las relaciones con el presidente de la República Bolivariana de Venezuela Hugo Chávez no han sido fáciles en razón de la supuesta colaboración y simpatías de las autoridades de Venezuela con las FARC-EP. Desde la misma llegada de Chávez al poder han sido incontables los incidentes entre los dos países. Tanto a Pastrana como a Uribe les ha disgustado las declaraciones de Hugo Chávez en el sentido de que: "El conflicto con la guerrilla colombiana lo estamos asumiendo con absoluta soberanía. Nos hemos declarado neutrales ante ese conflicto y dispuestos a contribuir en el proceso de paz. Así que, mantenemos una posición y si eso causa temores, que los cause; pero ya los trataremos." Inclusive Chávez ha señalado de manera pública que: "Yo he dicho, sí

${ }^{41}$ En diario Clarín, Buenos Aires, 21 de agosto, 2002.

${ }^{42}$ El Comercio, Quito, 12 de febrero, 2003.

${ }^{43}$ Hoy, Quito, 13 de febrero, 2003. 
estoy de acuerdo con el proceso de paz y sí nosotros estamos dispuestos a mediar el conflicto; porque si no, con qué moral, con qué fuerza puedo mediar, si estoy a favor de uno de los bandos." 44 El asunto es que la cancillería colombiana no ha tomado en serio la oferta de mediación del presidente venezolano, pues su neutralidad la considera como un acto previo al reconocimiento del estatus de fuerza beligerante de las FARCEP. Después del fallido golpe de Estado de abril de 2002, las relaciones con Venezuela han pasado por los sobresaltos del otorgamiento de asilo político a Pedro Carmona, autodeclarado presidente de facto durante el golpe y por las frecuentes denuncias de que Venezuela se ha convertido en el santuario de los principales líderes guerrilleros. También ha molestado a la ministra de Relaciones Exteriores de Colombia, Carolina Barco, la actitud soberana de los venezolanos al impedir que los radares y aviones de Estados Unidos realicen la interdicción de supuestas aeronaves ilegales que transitan por el espacio aéreo de Venezuela; medida que para la cancillería colombiana facilita el tránsito de drogas, narcotraficantes y guerrilleros. Obligados por la necesidad de suavizar el problema externo ante la magnitud de la convulsión interna, en abril de 2003, los presidentes Uribe y Chávez mantuvieron una reunión en un punto fronterizo en donde, de forma literal, fumaron la pipa de la paz.

En Brasil, el presidente Lula da Silva ha dado prioridad a la salida negociada en Colombia, razón por la que no aceptó la presión del presidente Uribe para considerar a las FARC-EP como un grupo terrorista; desligándose de las presiones de Estados Unidos a los países de la región en la política de "encerrar" a Colombia. Además, no se puede desconocer el poder de presión que pueda ejercer Brasil ante el aumento de la escalada militarista de Estados Unidos en la región norte de Sudamérica. Para Brasil es importante, desde el gobierno de Fernando Henrique Cardoso, el fortalecer un liderazgo en su política de hacer del sub-

${ }^{44}$ Heinz Dieterich Steffan et al., La cuarta vía al poder: Venezuela, Colombia, Ecuador, México, Editorial Quimera, 2001, pp. 92 y 94. 
continente una "región desmilitarizada", proyecto que cuenta con el apoyo del otro grande sudamericano, Argentina. El presidente de la Comisión de Defensa de la Cámara de Diputados de Brasil Aldo Rebelo habló a militares argentinos y brasileños sobre la necesidad de la integración de los países del Cono Sur a la "Nueva Política de Defensa" de Brasil. En el mismo acto, el entonces ministro de Defensa, Geraldo Quintão, expresó su preocupación por la agudización del conflicto colombiano, en la medida en que este afectará el equilibrio militar de la zona al estacionar por tiempo casi permanente grandes contingentes de tropas colombianas y, sobre todo, de Estados Unidos. Para Rebelo el problema está claro: "Sería una tragedia tener tropas norteamericanas en forma estable en Sudamérica". Por su lado el ministro Quintão aseguró que es el momento de crear una autonomía regional en asuntos militares y de seguridad para "disuadir intervenciones de otros países o bloques extrarregionales". Fue importante también su declaración de que "Brasil defiende la autodeterminación de los pueblos frente a conflictos internos". En otro orden, Quintão señaló una variante que con seguridad dejó inquietos a los asesores de seguridad de Estados Unidos: la posibilidad de incorporar en el proyecto de seguridad subcontinental a los países de África Occidental, con los que Brasil tiene una relación histórica, cultural y comercial, e inclusive una importante ayuda en entrenamiento y equipos militares. Otro general brasileño, Ronaldo Lessa, comandante por varios años en el Amazonas, habló de su temor que el conflicto colombiano sirva en el futuro cercano "para justificar una serie de intervenciones, inclusive sin el aval de la ONU o de la OEA." ${ }^{45}$

El tema del Plan Colombia se ha tratado de forma marginal en Perú, y la propuesta del primer ministro peruano, Javier Pérez de Cuellar, de la necesidad de la creación por parte de Estados Unidos de un "Plan Perú", no recibió apoyo siquiera de las fuerzas políticas oficialistas. Sin embargo, las consecuencias de su aplicación se hacen notar en Loreto,

${ }^{45}$ En diario Clarín, Buenos Aires, 4 de septiembre, 2002. 
departamento fronterizo con Colombia, donde la base militar de Nauta ha aumentado sus efectivos en más de 2000 soldados, con el apoyo logístico y el entrenamiento de fuerzas élite de Estados Unidos. Igual sucede en el puesto de Santa Lucía, en donde, desde el año 2000, hay más de medio centenar de soldados estadounidenses, realizando obras de infraestructura viales y la construcción de varias escuelas primarias, en espera de intervenir militarmente ante la agudización del conflicto en Colombia. Sin importar el fracaso de la política de sustitución de cultivos ilegales, en el Valle del río Apurimac, se han incrementado el número de efectivos policiales armados, caso del puesto policial de Palma Pampa. En la frontera con Bolivia, en el departamento de Madre de Dios, se construyó una importante base militar con asesoría directa de la DEA, en una zona sin historia de producción de hoja de coca ni tráfico de drogas, con la finalidad de consolidar el control regional de la zona amazónica de Colombia, Bolivia, Brasil, Ecuador y Perú. ${ }^{46}$

El que, guardadas las proporciones, si ha podido tener su propio Plan Colombia es Bolivia, y lo ha denominado "Plan Dignidad", con el fallido compromiso de erradicar cualquier vestigio de producción cocalera y convertir al territorio boliviano en "Cero Coca" en el año 2002. Un plan para un país en donde la producción de la hoja de coca tiene un peso histórico de carácter cultural, y cuya ilegalización ha facilitado la organización política de los productores, quienes hoy cuentan con una importante representación en el parlamento boliviano de oposición a la intromisión extranjera en los asuntos bolivianos, en particular por el veto a su candidato presidencial Evo Morales, por parte de la embajada de Estados Unidos en La Paz. ${ }^{47}$

${ }^{46}$ Véase entrevistas a líderes de los cocaleros de Perú y Ecuador participantes en el seminario "Movimientos sociales, participación y conflictos", realizado en Bogotá, en el artículo de Jaime Zuluaga, "El estigma de la sagrada hoja de coca", Periódico UN, Bogotá, 2001.

47 Ibid. 
A pesar de los vaivenes políticos en la región, en donde las adhesiones y distancias pueden variar por causas internas o por una acomodación al momento internacional, la política exterior de Uribe y su plan de seguridad regional han recibido un duro golpe con el rechazo general a la propuesta solicitando apoyo a su política de combate a las drogas en términos militares, en la que Colombia argumentaba la importancia del apoyo regional para "evitar que los grupos violentos busquen refugio en los países limítrofes y para ello queremos desarrollar acciones militares conjuntas con nuestros vecinos", dirigida a los presidentes de los países vecinos con Colombia, fuera rechazada de manera tajante por Brasil, Ecuador y Panamá; mientras Venezuela apenas la consideró y Perú ni se dio por enterado. ${ }^{48}$

\section{IV}

\section{ALGUNAS CONSIDERACIONES FINALES}

a) En materia de paz, la posición de Uribe desconoce la relación directa entre la grave marginación de la mayoría de la población colombiana y la violencia política. ${ }^{49}$ Hoy Colombia padece una profunda crisis económica luego de la implantación, desde finales de los años ochenta, de la ideología del libre mercado como panacea para solucionar el creciente deterioro en las condiciones de vida de una población de poco más de 40 millones, en la que 23 millones de habitantes padecen pobreza y más de 7 millones sufren de miseria. ${ }^{50}$ Mientras en 1996 el ingreso per cápita

48 A pesar de que John Walters, "zar" antidrogas de Estados Unidos, declaró que hay un "excepcional consenso" con América latina en el combate contra el narcotráfico. En diario Clarín, Buenos Aires, 21 de agosto, 2002.

${ }^{49}$ Marco Romero, "El disenso con Washington”, Periódico UN, núm. 45, Bogotá, 20 de abril, 2003.

${ }^{50}$ Asociación Nacional de Instituciones Financieras, Informe semanal, 23 de julio, 2001. 
era de US\$2 257, en 2001 se redujo a US\$1 890. Al comenzar el siglo XXI, 20\% de la población más pobre recibe apenas $4 \%$ del ingreso nacional. $28 \%$ no tiene agua potable. $40 \%$ no tiene alcantarillado. ${ }^{51}$ Reconocer estas cifras dramáticas y no desechar el latente peligro de una explosión social en Colombia es tarea prioritaria. Sin embargo, es tal la ceguera de Uribe que ha escogido el camino de la intensificación de la línea militar, más represión política, y olvida la magnitud del problema social, sin mostrar preocupación por la paulatina caída de la tasa de crecimiento anual que en los años setenta alcanzó un promedio mayor a 5\% anual, en los ochenta $3.4 \%$, en los noventa $2.7 \%$, y para los primeros años del nuevo siglo se estima, con optimismo, en poco más de $1 \%$. En su plan de desarrollo se aprecia un trato demagógico para los 3.5 millones de desempleados y los casi 7 millones de personas subempleadas. ${ }^{52}$

b) En definitiva, el presidente Uribe comete el mismo error de sus antecesores al no decirle al país lo que entiende por paz, ni lo qué espera de las FARC-EP y el ELN, y de sus compromisos ante un eventual proceso negociador. Los discursos presidenciales han sido ambiguos con respecto a los caminos de confrontación política y militar con los movimientos guerrilleros. Un día dice que los grupos armados ilegales sólo conocerán durante su mandato el garrote, para el día siguiente decir que su gobierno será generoso si el movimiento armado decide su entrega. Con este proceder el presidente Uribe sigue con la tradición presidencial de manejar el problema del conflicto político armado con menosprecio, a pesar de su gravedad, o con respuestas de corte electoral. Hace lo que conviene en las elecciones próximas, sin percibir la importancia de generar una verdadera política de Estado que a mediano y largo plazo enfoque las medidas acertadas para solucionar el conflicto.

${ }^{51}$ Profamilia, "Encuesta Nacional Demográfica 2002".

52 Departamento Administrativo Nacional de Estadística (DANE), "Encuesta Nacional de Hogares", febrero de 2002. 
Así mientras la guerrilla, en concreto las FARC-EP, insisten desde las negociaciones en Caracas y Tlaxcala, en 1992, en una misma agenda política, dividida en tres fases: una primera de diálogos con el gobierno y la sociedad para debatir temas de interés nacional; una segunda que sería una Asamblea Constituyente con carácter decisorio y con ellos armados; y una tercera, de gobierno de transición, en la que ellos se conservarían armados en ciertas zonas, en las que serían gobierno mientras se generaban condiciones de seguridad y se cumplían los acuerdos. ${ }^{53}$ La política de paz de Uribe, si es que existe, está enfocada en los avances represivos y en la consolidación de la política de intervención de Estados Unidos, amparada en la estrategia contra el terrorismo mundial del presidente George W. Bush, iraquizar o afganizar Colombia parece la estrategia de paz de Uribe, lo que significa, y los hechos lo corroboran a casi un año de inicio de su gobierno, una agudización de la confrontación armada y la congelación de cualquier posibilidad de apertura a la negociación política. Uribe sigue encomendando la suerte de Colombia a Dios y a la intromisión cada vez más evidente de Estados Unidos. ${ }^{54}$

c) Estados Unidos tiene un nuevo enemigo en América Latina. En principio, no hay más peligro de la posible implantación del comunismo en la región, ahora el peligro latente viene del tráfico de drogas, con una variante de fuertes implicaciones políticas, el llamado narcoterrorismo. Como una continuación de su política de intervención, Estados Unidos amplía la estrategia local de combate al narcotráfico del Plan Colombia,

${ }^{53}$ Comisión Temática de las FARC-EP y Carlos Lozano Guillén, FARC, el País que proponemos construir, Bogotá, Editorial Oveja Negra, 2001.

${ }^{54}$ Un hecho llamativo y que merece un estudio profundo es la reiterada invocación a Dios por parte del presidente Uribe, en un peligroso orden de predestinación fanática que lo exonera de su responsabilidad ante los colombianos y determina que la mayoría de sus actos políticos relacionados con el conflicto los "consulte" con Dios. Veánse discursos del presidente Uribe en http://www.presidencia.gov.co/discursos/ archivogen.htm. 
por una regional, denominada Plan Andino. ${ }^{55}$ Un proyecto que privilegia la represión a los productores pobres, sin afectar en nada a los grandes beneficiarios del narcotráfico mundial, e intensifica la confrontación armada con los grupos insurgentes de izquierda, acusados de financiar parte de sus actividades con el cobro de impuestos a los distribuidores nacionales de las drogas; sin descuidar el entorno geopolítico de la zona Andina y de la cuenca del Caribe.

En esta estrategia antinarcóticos, producida en su parte sustancial por la Secretaria de Defensa de Estados Unidos y por la DEA (Drugs Enforcement Agency), hay una mezcla de garrote y zanahoria: represión militar contra los cultivadores de coca y amapola con un programa de desarrollo alternativo, en donde la sustitución de cultivos es tenida en cuenta, pero olvidando un aspecto tan fundamental como la creación de infraestructura de vías y de mercadeo para los productos lícitos. La ambigüedad de cómo se llevan a la realidad estos programas dio margen para que se produjeran los efectos ya conocidos de desplazamientos masivos hacía las cabeceras municipales o hacia otras zonas del país. Además, debido a la fumigación extensiva, aumentaron los graves daños ecológicos en las inmensas llanuras y selvas del oriente y sur del país. ${ }^{56}$

d) Otro de los puntos para la polémica es que, fuera de un orden en estricto moral, es necesario aceptar que la relación de las FARC-EP, con los beneficios provenientes de la producción de cocaína, cumple una función económica estratégica, como lo fue en los años cincuenta la que tuvieron

55 Según Alejo Vargas, profesor de la Universidad Nacional de Colombia: "el Plan Colombia termina por engullirse el Plan de Desarrollo 'Cambio para Construir la Paz'." Alejo Vargas, El Plan Colombia: sus efectos sobre la guerra y la paz, Bogotá, REDUNIPAZ, 2000.

${ }^{56}$ S. Nyholm, representante de la oficina de fiscalización de estupefacientes de la ONU, declaró que en Colombia hay zonas en "donde los campesinos nunca han visto a un médico, un maestro o un técnico... Pero sí han visto la labor de los pilotos y de los aviones de fumigación”. Gloria Helena Rey, "Colombia: La siembra de la guerra”, Milenio Semanal, núm. 258, México, septiembre, 2002. 
las incipientes guerrillas liberales con el café, con el "impuesto" que exigían a los ricos hacendados cafetaleros; o con el vínculo estratégico que mantuvieron los rebeldes de Angola, Congo o Sudáfrica con el mercado ilegal de los diamantes y la explotación petrolera. Esto es muy importante dentro de las posibilidades de negociación en la medida que las FARC-EP necesitan llegar de nuevo a una mesa de negociaciones, en especial con participación de observadores internacionales, sin la imagen "enlodada" de narcoguerrilleros. La pretensión de esta guerrilla nunca ha sido el de convertirse en un cartel de las drogas y, a pesar de su actual debilidad en la línea política, mantienen como banderas centrales los cambios políticos que requiere la población colombiana para cerrar la profunda brecha social.

Insistir en una crítica moralista sólo contra el movimiento guerrillero es desconocer la intromisión del dinero del narcotráfico en todo el sistema político oficialista colombiano. ${ }^{57}$ Por ello es importante que se delimite de manera precisa el papel de las fortunas del narcotráfico como un agente favorecedor para todos los actores legales e ilegales del conflicto, y la necesaria implementación de una política que persiga de igual forma el tráfico de dinero, tanto los que benefician a las mafias de las drogas como al propio gobierno y a los grupos armados insurgentes, para su lavado en los mercados internacionales de apariencia legal, como los que operan bajo la protección de Estados Unidos y Europa.

e) El aumento de las llamadas milicias urbanas merece más atención. En términos rigurosos, es discutible que la mayoría de la población colombiana sea urbana. Si nos atenemos a la creciente migración campo-

57 A manera de ejemplo, hay que recordar que Ernesto Samper dedicó los cuatro años de su periodo presidencial, 1994-1998, a mantenerse en el cargo luego enfrentar, en un juicio amañado ante el Congreso, pruebas contundentes en su contra por la financiación de la campaña electoral por los carteles colombianos de la drogas. Su ministro de Defensa, Fernando Botero, fue apresado y acusado de enriquecimiento ilícito, pero no fueron determinantes las pruebas fehacientes que presentó para implicar a Samper. 
ciudad, forzada por la violencia desde finales de los años cincuenta, es cierto que hay mayoría de población asentada en las ciudades; pero hay que destacar que esa población a pesar de compartir el espacio urbano tiene una relación de orden marginal con la ciudad. Los cordones de miseria urbanos carecen todos de una cobertura de servicios básicos y sus habitantes sólo se integran a la ciudades, los más afortunados, a través del trabajo precario o informal y, la gran mayoría, en términos de criminalidad.

En las zonas urbanas, donde la violencia generada por el conflicto político se confunde con la inseguridad producto de las desigualdades sociales, hay una gran masa de población que se siente "fuera" de la confrontación guerrilla-gobierno y que se manifiesta en forma masiva cuando ocurren hechos graves, pero finalizado ese repudio vuelve a la pasividad y a la crítica desesperada en sus espacios cotidianos. Por su pasividad, el gobierno cree contar con esta población como su base social de apoyo, aunque los hechos han demostrado que es una opinión flotante en relación con los beneficios que puedan percibir a corto plazo. Este factor es muy importante de tomarse en cuenta, pues debido a la radicalización del conflicto, se puede inclinar a cualquiera de los contendientes. Como se comprueba sin dificultad al observar que las causas de enrolamientos en milicias guerrilleras o paramilitares no está determinando por tanto por factores políticos como por la retribución económica.

En definitiva, los en su mayoría jóvenes que integran las milicias, en apariencia muy politizados, están en realidad ensimismados en como resolver la incertidumbre de un país sin futuro visible. Tanto el (los) gobierno (s) como la guerrilla aparentan no darse cuenta de la desconfianza hacia el proyecto de Estado que ofrecen y de lo poco que han hecho para acercarse a las necesidades reales de esta población de carácter semiurbano, pero que conservan todavía muchos rasgos de la mentalidad campesina de la que fueron expulsados.

f) El alineamiento total de Colombia con Estados Unidos es para Uribe una lógica compensación a los recursos económicos y logísticos del 
Plan Colombia. Su apoyo solitario a Estados Unidos durante la invasión de Irak, junto con El Salvador y Nicaragua, países que ya tuvieron finalizado su plan contrainsurgente, apoya los principios del Patriot Act que dan carta blanca para una guerra global, preventiva y unilateral; no sólo contra los países del denominado "Eje del mal", sino con la persecución de cualquier intento de rechazo a las políticas económicas y autoritarias impulsadas por Estados Unidos. Colombia, con la renuncia de una política exterior plural que se guiaba por su activa participación en el Movimiento de Países No Alineados y la política de resolución de conflictos por la vía negociada en la región, como en Contadora y Esquipulas, se aísla de la política crítica de Latinoamérica y de los países más importantes de la Unión Europea apegándose a la soberbia diplomática de Estados Unidos que desafía el papel de organismos internacionales como las Naciones Unidas o a la Corte Internacional de Justicia. Además, Uribe, junto con César Gaviria, ex presidente neoliberal colombiano y actual Secretario General de la OEA, insisten en promover la intervención militar de otros países latinoamericanos en Colombia, utilizando fuerzas militares conjuntas, amparados en la reforma del Tratado Interamericano de Asistencia Recíproca, TIAR. Las relaciones de Estados Unidos y Colombia, en el presente y futuro cercano, se van a caracterizar por la importancia que el gobierno de Washington otorgue a la lucha contra las drogas y a la valoración de las circunstancias que precipitan la pérdida de su hegemonía geopolítica en la región; en particular por el papel de Brasil como líder regional y por el deterioro de su control sobre los gobiernos de Venezuela y Ecuador y los cambios que ocurran con su producción petrolera.

g) La suerte del proyecto militarista del presidente Álvaro Uribe correrá parejo a la suerte electoral de George W. Bush. El escenario futuro de Colombia muestra, a mediano plazo, una concomitancia total entre la política guerrerista de George W. Bush y la del presidente Álvaro Uribe. El afán relacionista de ambos mandatarios los mantendrá ocupados en tomar medidas que alivien la presión de sus electorados que ya sienten 
el desgaste de la fallida guerra contra el terrorismo. Estados Unidos, con su torpe política de intervención de Irak, y Colombia, con la implementación de la represión militar en zonas campesinas, con la aplicación del Plan Patriota, parte sustancial del Plan Colombia, manifiestan un creciente deterioro económico y social, al desviar para la guerra parte importante de los recursos de inversión social, lo que producirá inestabilidad y problemas de gobernabilidad en el futuro inmediato. A nivel regional, lo que suceda con Uribe y con los gobiernos de Venezuela, Brasil, Ecuador y Perú inclinará la balanza hacia una mayor intervención de Estados Unidos, en especial si, además del dominio petrolero, la intromisión directa en la zona le sirve a Bush como un sofisma para salir del atolladero de Irak. Ante el panorama desolador de la agudización del conflicto colombiano y su repercusión geopolítica regional es prioritaria la presión internacional, tanto de instancias gubernamentales como civiles progresistas de Europa y América Latina, para que presionen la apertura del diálogo entre los actores del conflicto colombiano y denuncien el plan intervencionista de Bush en la región. La internacionalización de la guerra en Colombia afectará el futuro de millones de personas de la región y aplazará, una vez más, las posibilidades de alcanzar mejoras en las deterioradas condiciones de vida de la mayoría de su población. Una paz negociada y justa seguirá siendo la única alternativa deseable.

\section{BIBLIOGRAFÍA BÁSICA}

Asociación Nacional de Instituciones Financieras, Informe semanal, Bogotá, 23 de julio, 2001.

CABAllero, Antonio, No es por aguar la fiesta..., Bogotá, Planeta, 1999 (Premios de Periodismo).

CODEES, Informe, Bogotá, 2002.

Comisión de Derechos Humanos de la ONU, Informes, febrero y abril, 2000. Comisión de Notables a la Mesa de Diálogo y Negociación, "Recomendación", Bogotá, septiembre de 2001. 
Comisión Temática de las FARC-EP y Carlos Lozano Guillén, FARC, el País que proponemos construir, Bogotá, Editorial Oveja Negra, 2001.

ChICOLA, Phil, "Conferencia conjunta con el presidente Uribe en el Carneggie Endowment", Washington, D.C., 25 de septiembre de 2002.

Decreto 1837 de 2002, "Estado de Conmoción Interior", Bogotá, Presidencia de la República, agosto de 2002.

Departamento Administrativo Nacional de Estadística (DANE), "Encuesta Nacional de Hogares", Bogotá, febrero de 2002.

Departamento de Estado de Estados Unidos, "Descripción del apoyo de Estados Unidos al Plan Colombia”, Washington, Programas de Información Internacional (PII) [Servicio Noticioso desde Washington], julio de 2000.

Diario Clarín, Buenos Aires, Argentina, 21 de agosto, 2002.

Diario Clarín, Buenos Aires, Argentina, 4 de septiembre, 2002.

Diario El Colombiano, primera página, Medellín, Colombia, 12 de noviembre, 2002.

Diario El Comercio, Quito, Ecuador, 12 de febrero, 2003.

Diario El Tiempo, "Editorial", Bogotá, Casa Editorial El Tiempo, 7 de mayo, 2003.

Diario El Tiempo, primera página, Bogotá, Casa Editorial El Tiempo, 5 de mayo, 2003.

Diario Hoy, Quito, Ecuador, 13 de febrero, 2003.

Diario The Washington Times, Estados Unidos, 19 de julio, 2002.

DIETERICH STEFFAN, Heinz et al., La cuarta vía al poder: Venezuela, Colombia, Ecuador, México, Editorial Quimera, 2001.

Fundación País Libre, Informe anual, Bogotá, 2002.

García Durán, Mauricio, De la Uribe a Tlaxcala. Procesos de Paz, Bogotá, CINEP, 1992.

GonZÁLEZ, Fernán, "Carta dirigida a Santiago Montenegro, director de Planeación Nacional, por el director del CINEP”, Bogotá, 16 de junio de 2000. Human Rights Watch, Informes, Washington, 2000.

OrozCo, Cecilia, ¿Y ahora qué? El futuro de la guerra y la paz en Colombia, Bogotá, El Áncora Editores, 2002.

Petras, James, La geoplolítica del Plan Colombia, La Habana, Siglo XXI, 2001.

Profamilia, Encuesta Nacional Demográfica, Bogotá, 2002.

Programa de televisión "Foro Interamericano", de la Voz de América, Washington, 26 de julio de 2002. 
Revista Cambio, "El proceso de paz no fracasó", Bogotá, Cambio Colombia, 21 de julio, 2002.

Revista Newsweek International, 25 de marzo, 2002.

REY, Gloria Helena, "Colombia: La siembra de la guerra", Milenio Semanal, núm. 258, México, septiembre, 2002.

ROMERo, Marco, "El disenso con Washington", Periódico UN, núm. 45, Bogotá, 20 de abril, 2003.

SchVARZ, Niko, "Sin título", Diario La República, Montevideo, 2 de mayo, 2003.

Secretariado del Estado Mayor Central de las FARC-EP, "Carta enviada a los ex presidentes de Colombia", Montañas de Colombia, 27 de abril, 2003.

Semanario Voz, "Entrevista a Manuel Marulanda Vélez", Bogotá, mayo, 2000. SwEIG, Julia E., “¿Qué tipo de guerra necesita Colombia?”, Foreign Affairs (en español), México, ITAM, otoño-invierno, 2002.

TrujILlo, Carlos Holmes [ed.], Al oído de Uribe, Bogotá, Editorial Oveja Negra, 2002.

Uribe Vélez, Álvaro, Plan Nacional de Desarrollo, Bogotá, Presidencia de la República, 2002.

"Discursos" en Internet (http://www.presidencia.gov.co/discursos/ archivogen.htm).

VARGAS, Alejo, El Plan Colombia: sus efectos sobre la guerra y la paz, Bogotá, REDUNIPAZ, 2000.

Zuluaga, Jaime, "El estigma de la sagrada hoja de coca", Periódico UN, Bogotá, 2001.

\section{BIBLIOGRAFÍA COMPLEMENTARIA}

Informe especial, "La guerra en blanco y negro", Revista Cambio, Bogotá, 12 de octubre, 2003.

Melo, Jorge Orlando, "Los paramilitares y su impacto sobre la política", en Francisco Leal Buitrago y León Zamosc, Al filo del caos. Crisis política en la Colombia de los años 80, Bogotá, Universidad Nacional/IEPRI/Tercer Mundo Editores, 1991.

Molano Bravo, Alfredo, "El Plan Colombia y el conflicto armado", Revista Número, núm. 27, enero, 2001.

NAgle, Luz Estella, Ayuda no Militar y la Agenda de Reforma Judicial del Plan Colombia, Washington, US Power Air, 2002. 
Navarro Wolf, Antonio, El Plan Colombia: implicaciones para el proceso de paz, México, CEIICH-UnAM, 2002.

Project Ploughshares, Armed Conflicts Report 2002, en http://www. ploughshares.ca/CONTENT/ACR/ACR00/ACR00-Colombia.html

RAMíREZ OCAMPO, Augusto, "La negociación es el único camino", en Jesús

Ortiz Nieves, La Paz. Análisis del proceso y propuestas para un nuevo sistema político en Colombia, Bogotá, Ediciones Aurora, 2000.

RANGEL, Alfredo, "La urbanización del conflicto", Revista Semana, Bogotá, 26 de agosto, 2001.

RESTREPO, Luis Carlos, Conflict and peace in Colombia: consequences and perspectives for the future, Washington, Kellogg Institute/Woodrow Wilson International Center for Scholars/ Ideas para la Paz, 2003.

REYEs PosadA, Alejandro, "Paramilitares en Colombia: Contexto, aliados y consecuencias", Análisis Político, núm. 12, Bogotá, IEPRI, enero-abril, 1991.

VALENCIA TOVAR, Álvaro, “A la fuerza pública no la puede reformar el enemigo", en Jesús Ortiz Nieves, La Paz. Análisis del proceso y propuestas para un nuevo sistema político en Colombia, Bogotá, Ediciones Aurora, 2000.

, Balance militar del 2003, Bogotá, El Tiempo/CLEPSIDRA, 2003.

VARGas VelÁsQueZ, Alejo, Las Fuerzas Armadas en el conflicto colombiano, Bogotá, Intermedio Editores, 2002. 